\title{
Facial profile and maxillary arch dimensions in unilateral cleft lip and palate children in the mixed dentition stage
}

\author{
Vellore Kannan Gopinath ${ }^{1}$, Ab Rani Samsudin ${ }^{1}$, Siti Noor Fazliah Mohd Noor ${ }^{2}$, \\ Hady Youssef Mohamed Sharab ${ }^{2}$
}

Correspondence: Dr. Vellore Kannan Gopinath

Email:vgopinath@sharjah.ac.ae

\begin{abstract}
'Department of Preventive and Restorative Dentistry, Department of Oral and Craniofacial Health Sciences, College of Dental Medicine, University of Sharjah, Sharjah, UAE,

${ }^{2}$ Department of Pediatrics Dentistry, School of Dental Sciences, Universiti Sains Malaysia, Malaysia
\end{abstract}

\section{ABSTRACT}

Objectives: The aim of this study was to evaluate the vertical and sagittal facial profile and maxillary arch width, depth, and length of patients with unilateral cleft lip and palate (UCLP) and to compare them with healthy noncleft children in the mixed dentition stage (7-13 years). Materials and Methods: This study is conducted at Hospital Universiti Sains Malaysia. UCLP group comprised 48 patients with nonsyndromic UCLP who have had the lip and palate repaired, whereas the control group comprised 48 healthy noncleft cases. The lateral cephalometrics measurements were used to determine the vertical height, sagittal depth of the face, and cranial base length and angle. Maxillary arch dimensions were measured on the study cast including arch width, depth, and length. Results: Vertical facial height and sagittal depth measurements showed a significant decrease $(P<0.05)$ in the mean growth pattern in UCLP group. The anterior cranial base length $(\mathrm{S}-\mathrm{N})$ was shorter in UCLP children $(P<0.001)$, while Ba-N length had no significant difference $(P=0.639)$. Nasion-Sella Tursica-Basion angle was significantly higher in the UCLP group $(P=0.016)$. Dental arch width with reference to canine-to-canine and first premolar-to-first premolar distance was significantly larger in control $(P=0.001)$. Conclusion: Mean vertical and sagittal facial dimensions in the UCLP children who do not undergo orthodontic treatment are significantly lesser in all directions of growth than healthy noncleft children. The maxillary dental arch had a normal depth but constricted in width and arch length.

Key words: Cleft lip and palate, facial profile, maxillary arch dimensions

\section{INTRODUCTION}

Cleft lip and palate (CLP) is the most common congenital malformation in the craniofacial region. Cleft lip (CL) and cleft palate (CP) occur due to a failure of the facial processes to fuse at the correct time. Majority of CLP appears to be due to a combination of genetics and environmental factors.$^{[1]}$ Epidemiological

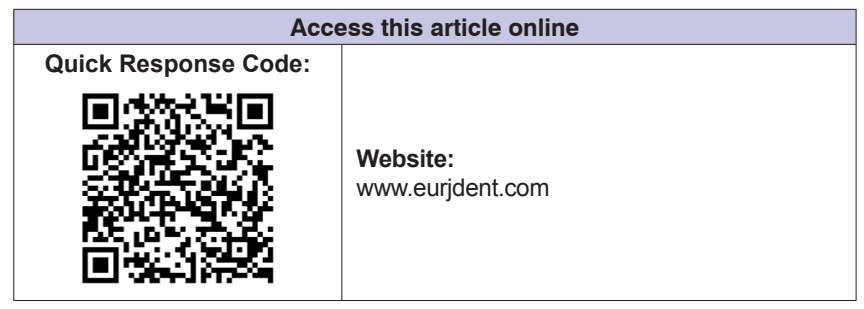

studies conducted on the incidence of CLP in Malaysian preschool children showed 1:1300 for CL and 1:1500 for $\mathrm{CP} \cdot{ }^{[2]}$ While the data from the international perinatal database of typical oral cleft ${ }^{[3]}$ reported an overall prevalence of CL with or without CP was $9.92 / 10,000$, CL 3.28/10,000 and that of CLP was 6.64/10,000.

This is an open access article distributed under the terms of the Creative Commons Attribution-NonCommercial-ShareAlike 3.0 License, which allows others to remix, tweak, and build upon the work non-commercially, as long as the author is credited and the new creations are licensed under the identical terms.

For reprints contact: reprints@medknow.com

How to cite this article: Gopinath VK, Samsudin AR, Noor SN, Sharab HY. Facial profile and maxillary arch dimensions in unilateral cleft lip and palate children in the mixed dentition stage. Eur J Dent 2017;11:76-82.

DOI: 10.4103/ejd.ejd_238_16 
Most of the studies have evaluated the craniofacial dimension of the patients with CLP at the end of the facial growth period, while fewer studies report facial growth deficiencies before the completion of growth period. ${ }^{[4-6]}$ CLP affects craniofacial growth in vertical, sagittal, and transverse plane. Concave facial profile observed in cleft patients is due to sagittal deficiency of the midface which is progressive and can be observed from early years of the individual till maturity. ${ }^{[7]}$ Studies comparing dentofacial morphology of children with CLP with that of normal children have shown a significant variation in the morphologic parameters. ${ }^{[8,9]}$

Dental arch dimensions of the maxillary complex in patients with CLP seem compromised. Studies have shown that maxillary arch interdental width and arch length were significantly smaller in patients with CLP when compared to normal group in mixed and permanent dentition period. ${ }^{[10]}$ Factors such as genetic, facial pattern, severity of the cleft, and effects of surgery have been shown to affect maxillary arch dimensions. ${ }^{[11]}$ Dissaux et al. ${ }^{[12]}$ reported that Veau-Wardill-Kilner palatoplasty results in transversal maxillary deficiency and retromaxillary.

Since early orthopedic and orthodontic interventions may result in a better outcome, there is a need to study the facial growth during the mixed dentition stage. There are no data available regarding the facial profile and maxillary arch dimension of patients with CLP in Malaysia. This information is vital for the clinician to plan orthodontic treatment, especially in mixed dentition stage which is favored by rapid growth facilitating good treatment outcome. Hence, the aim of this study was to evaluate the vertical and sagittal facial profile and maxillary arch width, depth, and length of patients with unilateral CLP (UCLP) and their functional characteristics and to compare them with healthy noncleft children in the mixed dentition stage (7-13 years).

\section{MATERIALS AND METHODS}

This study was conducted at Hospital Universiti Sains Malaysia (HUSM), which is a tertiary referral hospital with a multidisciplinary CLP management team. The source population was both male and female Malaysian children attending the outpatient dental clinic at HUSM. This study was carried out after obtaining the approval from the Ethics Committee of University Science Malaysia as per the Declaration of Helsinki. The parents or guardians of the cases involved in this study were informed regarding the procedure with written consent.

The study sample comprised repaired UCLP children and healthy noncleft children in the age range between 7 and 13 years. UCLP children were selected randomly from hospital dental patients list over a 2-year period (from January 2008 to December 2010). UCLP group comprised 48 repaired patients with CLP who have had the lip and palate repaired but have not received any form of orthodontic treatments. Children with syndrome, neurological impairment, mental retardation, and systemic diseases were excluded from the study. In the present sample, correction of CL was undertaken to utilize the standard Millard rotation and advancement technique between 3 and 6 months of age and palatal repair utilizing the Veau-Wardill-Kilner palatoplasty technique was performed between the age of 8 and 18 months in all cases participating in the experimental group. The control group comprised 48 healthy noncleft cases in the age range between 7 and 13 years with no history of orthodontic treatment reporting to the outpatient dental clinic at HUSM for routine dental treatment. The sample size used in this study is adequate to detect a difference of $5^{\circ}$ in cranial base N-S-Ba angle and $4 \mathrm{~mm}$ in arch depth analysis using a power of $80 \%$ and $\alpha$ level of 0.05 (two-tailed). Lateral cephalometric X-ray and dental impressions were taken for cephalometric analysis, and construction of dental cast study models for all cases in both groups enrolled in the study.

Eight linear measurements were done to determine the vertical height of the face, and 12 linear measurements were obtained to determine its sagittal depth. ${ }^{[13]}$ The

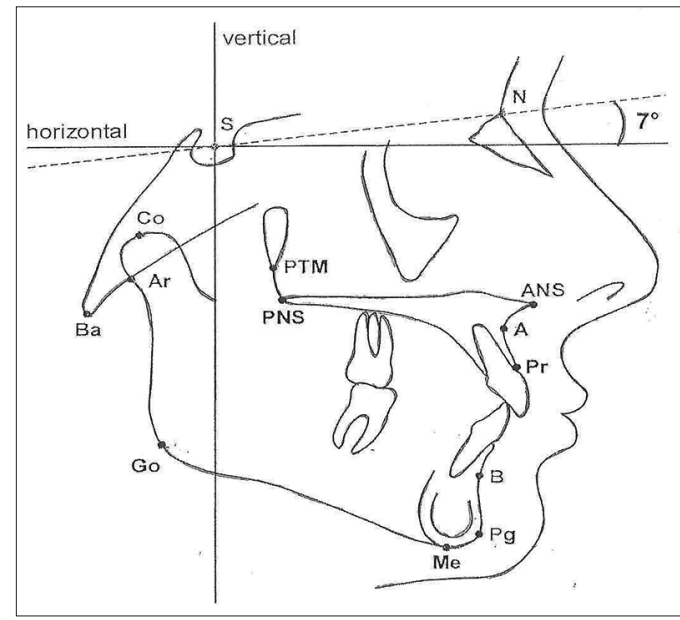

Figure 1: Tracing of lateral cephalogram showing landmarks 
cranial base length and angle were measured as described by Trotman and Ross. ${ }^{[6]}$ All landmarks used for facial and cranial base measurements are shown in Figure 1. Maxillary arch dimensions were measured on the study cast include arch width, depth, and length [Figure 2]. Intercanine width was obtained by measuring the distance between the midpoint of the left and right canines, while the interfirst premolar width (IPW) was the distance between the premolars or deciduous molars ( $1^{\text {st }}$ and $\left.2^{\text {nd }} I P W\right)$, and intermolar width (IMW) was the distance between the first permanent molar $\left(1^{\text {st }} \mathrm{IMW}\right) \cdot{ }^{[5]}$ Maxillary arch depth (sagittal length of palate) was obtained by measuring the distance between the mesial point of the two central incisors or midpoint to the central diastema and the midpoint of the line extending from the mesial anatomic contact point of left to the right first permanent or deciduous molar. ${ }^{[5]}$ Arch length was achieved by measuring the line passing through the midpoint between the distal surfaces of the deciduous second molar or the first permanent molar to the midpoint between the central incisors. ${ }^{[14]}$ The measurements were made to the nearest $0.5 \mathrm{~mm}$ using digital sliding calipers (Digimatic Caliper, Japan).

Lateral cephalometric and dental cast model measurements were done by a single investigator. Measurements were tested for reproducibility by randomly selecting one study case from UCLP group and all lateral cephalometric linear and angular measurements and study cast were measured 3 times on three separate days within 1 week. The degree of reproducibility which is the interclass correlation coefficient was nearly one (1.00) which indicates that measurements were almost identical or with negligible error.

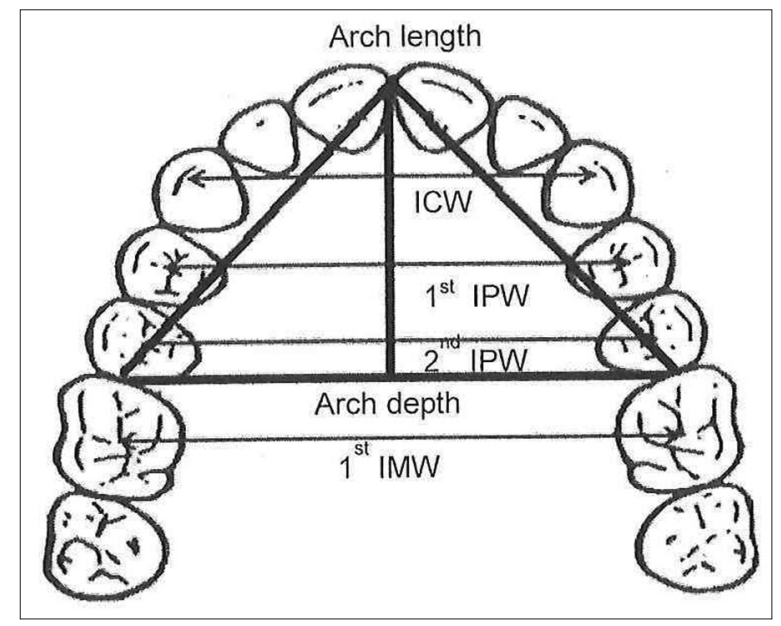

Figure 2: Anatomical landmark of the upper dental cast

\section{Statistical analysis}

All analyses were conducted using IBMSPSS Statistics for Windows, Version 20.0. IBM Corp., Inc., Armonk, NY, USA, in which the significant alpha level was 0.05 (two-tailed). Inference to the study population was made with $95 \%$ of confidence interval.

\section{RESULTS}

Vertical and sagittal facial profile measurements of CLP children and control group during mixed dentition stage (7-13 years old) are given in Tables 1 and 2. Vertical facial height and sagittal depth measurements showed a significant decrease $(P<0.05)$ in the mean growth pattern in UCLP group for all measurements except for nasion-anterior nasal spine line in the vertical height measurement which showed no significant difference between UCLP and control groups. Mean values in cranial base length and cranial base flexure angle are shown in Table 3. The anterior cranial base length (S-N) was shorter in UCLP children $(P<0.001)$, whereas Ba-N length had no significant difference $(P=0.639)$. Nasion-sella turcica-basion angle was significantly higher in the UCLP group $(P=0.016)$. Mandibular ramus height (Ar-Go and Co-Go) and body length (Go-Pg, Ar-Pg) were significantly lower in UCLP group [Tables 1 and 2].

Maxillary arch dimensions which include dental arch width, arch depth, and arch length are shown in Table 4. Dental arch width with reference to canine-to-canine and first premolar-to-first premolar distance was significantly larger in control $(P=0.001)$, whereas the arch width in the second premolar and the first molar region showed no difference between the groups. Although the arch depth did not show any significant difference between the groups tested, there was a significant reduction in arch length in UCLP group $(P<0.001)$ Table 4.

\section{DISCUSSION}

HUSM run a multidisciplinary CLP clinic since the year 1994. All authors in this study are the members of the multidisciplinary team. The comprehensive care given by the team includes primary lip and palate repair, alveolar bone grafting, orthodontic, speech therapy, and hearing and pediatric dental care. There are still a smaller number of cleft children who misses orthodontic treatment due to their residential distance being very far from the center. These are the cleft children who have been selected as a part of the inclusion criteria. 
Gopinath, et al.: Facial profile and maxillary arch dimensions in UCLP

\begin{tabular}{|c|c|c|c|c|c|}
\hline Variable & Group & Mean (SD), mm & Adjusted mean $(95 \% \mathrm{Cl}), \mathrm{mm}$ & $F$ statistic (df) & $P^{b}$ \\
\hline \multirow[t]{2}{*}{$\mathrm{N}-\mathrm{Me}$} & UCLP & $95.0(12.8)$ & $95.6(92.5-98.7)$ & $7.65(1,70)$ & 0.007 \\
\hline & Control & $103.3(6.3)$ & $103.0(98.7-107.3)$ & & \\
\hline \multirow[t]{2}{*}{ N-ANS } & UCLP & $41.7(8.3)$ & $42.0(40.1-44.0)$ & $1.27(1,70)$ & 0.263 \\
\hline & Control & $44.2(3.4)$ & $44.0(41.3-46.7)$ & & \\
\hline \multirow[t]{2}{*}{ ANS-Me } & UCLP & $54.6(8.1)$ & $54.9(52.8-57.0)$ & $16.41(1,70)$ & $<0.001$ \\
\hline & Control & $62.5(5.1)$ & $62.1(59.3-65.0)$ & & \\
\hline \multirow[t]{2}{*}{$\mathrm{N}-\mathrm{Pr}$} & UCLP & $53.9(9.2)$ & $54.2(51.9-56.5)$ & $7.22(1,70)$ & 0.009 \\
\hline & Control & $59.7(4.5)$ & $59.5(56.3-62.6)$ & & \\
\hline \multirow[t]{2}{*}{ S-PNS } & UCLP & $36.1(6.2)$ & $36.3(34.8-37.9)$ & $15.03(1,70)$ & $<0.001$ \\
\hline & Control & $41.8(3.6)$ & $41.5(39.4-43.7)$ & & \\
\hline \multirow[t]{2}{*}{ S-Go } & UCLP & $58.9(8.8)$ & $59.5(57.3-61.7)$ & $20.81(1,70)$ & $<0.001$ \\
\hline & Control & $68.7(6.5)$ & $68.0(65.1-71.0)$ & & \\
\hline \multirow[t]{2}{*}{ Ar-Go } & UCLP & $36.0(6.0)$ & $36.3(34.6-37.9)$ & $17.49(1,70)$ & $<0.001$ \\
\hline & Control & $42.5(5.5)$ & $42.2(39.9-44.4)$ & & \\
\hline \multirow[t]{2}{*}{ Co-Go } & UCLP & $48.0(7.3)$ & $48.4(46.5-50.3)$ & $27.49(1,70)$ & $<0.001$ \\
\hline & Control & $57.4(5.9)$ & $56.9(54.3-59.5)$ & & \\
\hline
\end{tabular}

${ }^{a}$ Adjusted for age and sex, ${ }^{b}$ ANCOVA. N-Me: Nasion-menton line, N-ANS: Nasion-anterior nasal spine line, ANS-Me: Anterior nasal spine-menton line, N-Pr: Nasion-prosthion line, S-PNS: Posterior nasal spine-sella turcicaline, S-GO: Sella turcica-gonion line, Ar-Go: Articulare-gonion line, Co-Go: Condylion-gonion line, ANCOVA: Analysis of covariance, SD: Standard deviation, Cl: Confidence interval, UCLP: Unilateral cleft lip and palate

\begin{tabular}{|c|c|c|c|c|c|}
\hline Variable & Research group & Mean (SD), mm & Adjusted mean ${ }^{\mathrm{a}}(95 \% \mathrm{Cl}), \mathrm{mm}$ & $F$ statistic (df) & $P^{b}$ \\
\hline \multirow[t]{2}{*}{ S-N } & UCLP & $55.5(6.4)$ & $55.8(54.1-57.4)$ & $18.84(1,70)$ & $<0.001$ \\
\hline & Control & $61.9(3.9)$ & $61.8(59.6-64.0)$ & & \\
\hline \multirow[t]{2}{*}{ S-A } & UCLP & $65.2(8.1)$ & $65.7(63.8-67.7)$ & $26.07(1,70)$ & $<0.001$ \\
\hline & Control & $74.6(5.1)$ & $74.3(71.6-77.0)$ & & \\
\hline \multirow[t]{2}{*}{ Ba-A } & UCLP & $76.2(11.4)$ & $76.6(73.7-79.4)$ & $4.60(1,70)$ & 0.035 \\
\hline & Control & $81.9(6.3)$ & $81.8(77.9-85.7)$ & & \\
\hline \multirow[t]{2}{*}{ PNS-A } & UCLP & $40.6(5.4)$ & $40.9(38.9-42.8)$ & $4.16(1,70)$ & 0.045 \\
\hline & Control & $44.4(8.7)$ & $44.3(41.6-46.9)$ & & \\
\hline \multirow[t]{2}{*}{ PTM-A } & UCLP & $41.1(4.8)$ & $41.4(40.1-42.6)$ & $18.90(1,70)$ & $<0.001$ \\
\hline & Control & $46.0(3.9)$ & $46.0(44.3-47.7)$ & & \\
\hline \multirow[t]{2}{*}{ S-Pr } & UCLP & $70.9(9.0)$ & $71.4(68.9-73.9)$ & $18.35(1,70)$ & $<0.001$ \\
\hline & Control & $81.0(8.7)$ & $80.6(77.2,84.0)$ & & \\
\hline \multirow[t]{2}{*}{$\mathrm{Ba}-\mathrm{Pr}$} & UCLP & $79.3(12.2)$ & $79.8(76.7-82.8)$ & $6.95(1,70)$ & 0.010 \\
\hline & Control & $86.8(6.8)$ & $86.6(82.5-90.8)$ & & \\
\hline \multirow[t]{2}{*}{ S-B } & UCLP & $86.1(10.3)$ & $86.7(84.0-89.3)$ & $19.66(1,70)$ & $<0.001$ \\
\hline & Control & $97.0(7.2)$ & $96.5(93.0-100.1)$ & & \\
\hline \multirow[t]{2}{*}{ S-Pg } & UCLP & $95.2(11.6)$ & $96.0(93.1-98.9)$ & $13.44(1,70)$ & $<0.001$ \\
\hline & Control & $105.7(8.1)$ & $105.0(101.1-109.0)$ & & \\
\hline \multirow[t]{2}{*}{$\mathrm{Ba}-\mathrm{Pg}$} & UCLP & $87.8(13.8)$ & $88.5(85.0-91.9)$ & $5.26(1,70)$ & 0.025 \\
\hline & Control & $95.7(8.4)$ & $95.3(90.5-100.0)$ & & \\
\hline \multirow[t]{2}{*}{ Go-Pg } & UCLP & $57.1(8.2)$ & $57.4(55.1-59.7)$ & $3.87(1,70)$ & 0.053 \\
\hline & Control & $61.5(7.7)$ & $61.3(58.2-64.5)$ & & \\
\hline \multirow[t]{2}{*}{ Ar-Pg } & UCLP & $83.7(10.8)$ & $84.4(81.6-87.3)$ & $11.03(1,70)$ & $<0.001$ \\
\hline & Control & $92.9(9.0)$ & $92.5(88.6-96.4)$ & & \\
\hline
\end{tabular}

${ }^{a}$ Adjusted for age and sex, ${ }^{b}$ ANCOVA. S-N: Sella turcica-nasion, S-A: Sella turcica-A point, Ba-A: Basion-A point, PNS-A: Posterior nasal spine-A point, PTM-A: Pterygomaxillary fissure-A point, S-Pr: Sella turcica-prosthion, Ba-Pr: Basion-prosthion, S-B: Sella turcica-B point, S-Pg: Sella turcica-pogonion, Ba-Pg: Basion-pogonion, Go-Pg: Gonion-pogonion, Ar-Pg: Articulare-pogonion, ANCOVA: Analysis of covariance, SD: Standard deviation, Cl: Confidence interval, UCLP: Unilateral cleft lip and palate, SD: Standard deviation, Cl: Confidence interval

Comparing the difference in facial growth during mixed dentition between nonsyndromic CLP to healthy noncleft children revealed a significant decreased in vertical and sagittal facial dimension in
UCLP group. The cranial base length (Ba-N) is also shorter in the UCLP group. Previous dentocraniofacial morphology studies on children with CLP have also shown reduced sagittal and vertical dimensions of 


\begin{tabular}{|c|c|c|c|c|c|}
\hline Variable & Research group & Mean (SD) & Adjusted mean ${ }^{a}(95 \% \mathrm{Cl})$ & $F$ statistic (df) & $P^{b}$ \\
\hline \multirow[t]{2}{*}{ Ba.N } & UCLP & $89.2 \mathrm{~mm}(13.7)$ & $89.7 \mathrm{~mm}(86.3-93.2)$ & $0.22(1,70)$ & 0.639 \\
\hline & Control & $91.5 \mathrm{~mm}(7.7)$ & $91.1 \mathrm{~mm}(86.4-95.9)$ & & \\
\hline \multirow[t]{2}{*}{ N.S.Ba } & UCLP & $135.2^{\circ}(10.5)$ & $134.7^{\circ}(131.8-137.7)$ & $6.09(1,70)$ & 0.016 \\
\hline & Control & $128.0^{\circ}(9.7)$ & $128.6^{\circ}(124.6-132.6)$ & & \\
\hline
\end{tabular}

${ }^{a}$ Adjusted for age and sex, ${ }^{\mathrm{b} A N C O V A}$. Ba.N: Basion-nasion, N.S.Ba: Nasion-sella turcica-basion, ANCOVA: Analysis of covariance, SD: Standard deviation, Cl: Confidence interval, UCLP: Unilateral cleft lip and palate

\begin{tabular}{|c|c|c|c|c|c|c|}
\hline Variable & Research group & $n$ & Mean (SD), mm & Adjusted mean ${ }^{\mathrm{a}}(95 \% \mathrm{Cl}), \mathrm{mm}$ & $F$ statistic (df) & $P^{b}$ \\
\hline \multicolumn{7}{|l|}{ Arch width } \\
\hline \multirow[t]{2}{*}{ Canine } & UCLP & 38 & $26.9(4.3)$ & $26.8(25.6-28.1)$ & $14.47(1,60)$ & $<0.001$ \\
\hline & Control & 26 & $30.6(2.3)$ & $30.5(29.1-32.0)$ & & \\
\hline \multirow[t]{2}{*}{ First premolar } & UCLP & 39 & $32.1(5.2)$ & $32.2(30.8-33.5)$ & $11.40(1,61)$ & 0.001 \\
\hline & Control & 26 & $36.1(2.3)$ & $35.9(34.2,37.6)$ & & \\
\hline \multirow[t]{2}{*}{ Second premolar } & UCLP & 38 & $39.1(5.8)$ & $39.2(37.6-40.8)$ & $1.97(1,60)$ & 0.165 \\
\hline & Control & 26 & $41.3(2.6)$ & $40.9(39.0-42.8)$ & & \\
\hline \multirow[t]{2}{*}{ First molar } & UCLP & 46 & $46.7(6.0)$ & $46.7(45.2-48.2)$ & $0.06(1,68)$ & 0.800 \\
\hline & Control & 26 & $46.4(2.6)$ & $46.3(44.3-48.3)$ & & \\
\hline \multicolumn{7}{|l|}{ Arch depth } \\
\hline \multirow[t]{2}{*}{ Perpendicular } & UCLP & 46 & $29.3(4.9)$ & $29.4(28.1,30.8)$ & $0.09(1,68)$ & 0.765 \\
\hline & Control & 26 & $30.0(3.5)$ & $29.8(28.0-31.5)$ & & \\
\hline \multirow{2}{*}{ Arch length } & UCLP & 43 & $61.2(5.8)$ & $61.1(59.5-62.7)$ & $13.78(1,65)$ & $<0.001$ \\
\hline & Control & 26 & $65.9(3.8)$ & $66.1(64.0-68.2)$ & & \\
\hline
\end{tabular}

the midface producing a tendency toward a Class III skeletal pattern which is comparable to the present findings. ${ }^{[15-17]}$ In the present study, cranial base flexure angle (N-S-Ba) was significantly higher in UCLP group when compared to normal children. There is a tendency to postulate that the large N-S-Ba angle is associated with retruded maxilla resulting in skeletal Class III relationship. However, comparable to the present findings, studies conducted on unilateral CLP patients with favorable maxillary growth showed a high Sella-Nasion-A point angle that was similarly associated with a larger cranial base angle. ${ }^{[18]}$ On the other hand, it is interesting to note that an acute cranial base angle is associated with Class III malocclusion in normal individuals. ${ }^{[19,20]}$ However, in contrast to this in the present study, an obtuse cranial base angle observed in UCLP children has resulted in a similar Class III facial profile. This could be due to a smaller vertical and sagittal dimensions of the midface and a significantly shorter anterior cranial base (SN) observed in this study. As the maxilla is structurally hanging down from the anterior cranial base, a shorter anterior cranial base contributes to a shallower midface and positioned the maxilla and maxillary dental arch in a more posterior position in relation to the mandible.
Maxillary arch width in the intercanines and the interfirst premolar regions seems narrower in UCLP group, while the dimensions in the second premolar and first molar regions were lesser but not statistically significant. Earlier studies assessing linear maxillary arch dimensions among UCLP and normal children during the mixed dentition stage have shown significantly greater values in children without CLP as presently observed in the control group. ${ }^{[21]}$ Reduction in the maxillary arch dimensions noted in the present study could be attributed to the scar tissue development following surgical repair procedures. ${ }^{[22]}$ It could also be due to the abnormal inferior position of the tongue as a result of the hyoid bone being positioned caudally in Malaysian infants ${ }^{[23]}$ that may have also contributed to maxillary constriction. Since it is known that under normal circumstances, the dorsum of the tongue that is anatomically and physiologically positioned against the palate at rest maintains the maxillary arch width by counteracting the contracting forces from the buccinator muscles. ${ }^{[24]}$ However, many more authors put the blame on the surgical scar as the main cause of maxillary constriction.

The combine $\mathrm{CP}$ team at HUSM advocates rigid treatment timing in their surgical treatment protocol, 
based on sound scientific judgments. The decreased facial profile measurements and constriction of maxillary arch noted in the present study in UCLP group children could be attributed to early surgical correction protocols. In the present sample, correction of CL was undertaken to utilize the standard Millard rotation and advancement technique between 3 and 6 months of age and palatal repair utilizing the Veau-Wardill-Kilner palatoplasty technique was performed between the age of 8 and 18 months. The present studies have shown that early palatoplasty inhibits midface and maxillary growth in all directions and the surgical site was shown to grow the least. ${ }^{[25]}$ This could be due to the timing of surgery leading to early scar contraction, ${ }^{[26]}$ and midface retrusion occurs from the ages of 8 to 15 years. ${ }^{[27]}$ Hence, it has been suggested that postponement of hard palate closure to age of 9-11 years ${ }^{[28]}$ or delaying it later till 15 years of age will avoid facial growth interference. ${ }^{[25]}$ Despite the evidence and recommendations proposed on the favorably delayed timing of primary $\mathrm{CP}$ repair, this cleft center in HUSM like many other cleft centers around the world still performs early primary repair operations because it facilitates ease of feeding and good speech development and a strong desire from the patients' parents themselves to undertake early repair of CLP for their children.

It is well established that CLP children have a Class III dental and skeletal malocclusion. ${ }^{[15]}$ In this study, the maxillary arch depth was not significantly different between UCLP and control group children. However, anterior cranial base length (SN) showed a significant shorter linear measurement in UCLP children, which could have contributed to posterior positioning of the maxilla. This is supported by studies which indicate that a decreased anterior cranial base length results in skeletal Class III in patients with maxillary deficiencies. ${ }^{[29]}$ Therefore, in the age group, studied relative Class III dental malocclusion is due to a shorter anterior cranial base (SN) rather than a shorter palate depth.

In this study, linear measurement involving Ar-Go, Co-GO, Go-Pg, and Ar-Pg all showed significantly lesser values in UCLP children in comparison with control group thus reflecting a significant reduction in vertical height of the ramus and a short mandibular body and total mandibular length. Paradowska-Stolarz and Kawala ${ }^{[30]}$ also confirmed the difference in mandibular bone length in patients with CLP when compared with healthy individuals. This smaller mandibular dimension should rationally fit compatibly with smaller dimension of the maxilla which is already in a more retruded position. However, contrary to this fact, almost all CLP children showed Class III dental and skeletal malocclusion. Sundareswaran and Nipun $^{[31]}$ examined the relationship of the mandible to the cranial base and found the glenoid fossa is positioned more cranially and anteriorly in UCLP individuals, clinically contributing to the mandibular prominence and concave facial profile. In the present study, mandibular dimension in patients with CLP was smaller when compared to control individuals which are comparable to Hermann et al. ${ }^{[32]}$ reporting the mean mandibular length in infants with CLP was about $4 \mathrm{~mm}$ shorter when compared to unilateral incomplete CL infants. While Sundareswaran and Nipun ${ }^{[31]}$ reported normal mandibular length in UCLP individuals but Singh et al. ${ }^{[33]}$ observed size increase in ramus and mandible in CLP children. However, this study showed that $\mathrm{S}-\mathrm{B}, \mathrm{Ba}-\mathrm{Pg}$, and $\mathrm{S}-\mathrm{Pg}$ liner distances are significantly less in UCLP group compared to control reflecting difference in forward and downward displacements of the mandibular growth. In view of the differences noted, mandibular dimensions in CLP children need further investigation.

Reduction in maxillary arch length in UCLP group children noted in the present study could be attributed to untreated caries in primary teeth. ${ }^{[34]}$ and a high incidence of hypodontia reported in patients with UCLP. ${ }^{[35]}$ Abd Rahman et al. ${ }^{[36]}$ have also reported a $44.9 \%$ prevalence of hypodontia among Malaysian nonsyndromic UCLP children in the age range of 3-12 years. Hence, emphasis should be place on the pediatric dentist and general practitioners to restore carious primary teeth and space management to preserve the arch length.

Compromised facial and maxillary growth in 7-13-year-old children with UCLP in the present study warrant early initiation of myofunctional therapy to facilitate growth modifications and redirecting favorable facial growth. Supporting this, studies have shown that the utilization of tongue appliances could transfer the force of the tongue to maxillary complex resulting in a normal sagittal maxillomandibular relationship in 7-9-year-old patients with CLP. ${ }^{[37]}$ Maxillary expansion and distraction, chin-cap, and high-pull headgear are advocated to treat patients with CLP in the age of 11-12 years with a concave profile. ${ }^{[38]}$ As it is still doubtful if there could be a undisputed agreement among cleft centers to be able to advocate delayed primary repair of the palate to achieve unrestricted facial growth. 


\section{CONCLUSION}

The mean midfacial and lower facial dimensions in children with UCLP who do not undergo orthodontic treatment are significantly lesser in all directions of growth than healthy noncleft children. The maxillary dental arch had a normal depth but constricted in width and arch length. They also present with a Class III dental and skeletal pattern, despite having a relatively shorter mandibular length when compared to the matched control.

\section{Financial support and sponsorship \\ Nil.}

\section{Conflicts of interest}

There are no conflicts of interest.

\section{REFERENCES}

1. Cura F, Böhmer AC, Klamt J, Schünke H, Scapoli L, Martinelli M, et al. Replication analysis of 15 susceptibility loci for nonsyndromic cleft lip with or without cleft palate in an Italian population. Birth Defects Res A Clin Mol Teratol 2016;106:81-7.

2. Dental Services Division. Dental epidemiological survey of preschool children in Malaysia. Kuala Lumpur, MY: Ministry of Health Malaysia; 1995.

3. IPDTOC Working Group. Prevalence at birth of cleft lip with or without cleft palate: Data from the International Perinatal Database of Typical Oral Clefts (IPDTOC). Cleft Palate Craniofac J 2011;48:66-81.

4. Del Guercio F, Meazzini MC, Garattini G, Morabito A, Semb G, Brusati R. A cephalometric intercentre comparison of patients with unilateral cleft lip and palate at 5 and 10 years of age. Eur J Orthod 2010;32:24-7.

5. Heidbuchel KL, Kuijpers-Jagtman AM. Maxillary and mandibular dental-arch dimensions and occlusion in bilateral cleft lip and palate patients form 3 to 17 years of age. Cleft Palate Craniofac J 1997;34:21-6.

6. Trotman CA, Ross RB. Craniofacial growth in bilateral cleft lip and palate: Ages six years to adulthood. Cleft Palate Craniofac J 1993;30:261-73.

7. Silva Filho OG, Calvano F, Assunção AG, Cavassan AO. Craniofacial morphology in children with complete unilateral cleft lip and palate: A comparison of two surgical protocols. Angle Orthod 2001;71:274-84.

8. Trotman CA, Papillon F, Ross RB, McNamara JA Jr., Johnston LE Jr. A retrospective comparison of frontal facial dimensions in alveolar-bone-grafted and nongrafted unilateral cleft lip and palate patients. Angle Orthod 1997;67:389-94.

9. Athanasiou AE, Tseng CY, Zarrinnia K, Mazaheri M. Frontal cephalometric study of dentofacial morphology in children with bilateral clefts of lip, alveolus and palate. J Craniomaxillofac Surg 1990;18:49-54.

10. Athanasiou AE, Mazaheri M, Zarrinnia K. Dental arch dimensions in patients with unilateral cleft lip and palate. Cleft Palate J 1988;25:139-45.

11. Honda Y, Suzuki A, Ohishi M, Tashiro H. Longitudinal study on the changes of maxillary arch dimensions in Japanese children with cleft lip and/or palate: Infancy to 4 years of age. Cleft Palate Craniofac J 1995;32:149-55.

12. Dissaux C, Grollemund B, Bodin F, Picard A, Vazquez MP, Morand B, et al. Evaluation of 5-year-old children with complete cleft lip and palate: Multicenter study. Part 2: Functional results. J Craniomaxillofac Surg 2016;44:94-103.

13. Sarnat BG. Some methods of assessing postnatal craniofaciodental growth: A retrospective of personal research. Cleft Palate Craniofac J 1997;34:159-72.

14. Abu Alhaija ES, Qudeimat MA. Occlusion and tooth/arch dimensions in the primary dentition of preschool Jordanian children. Int J Paediatr Dent 2003;13:230-9.
15. Holst AI, Holst S, Nkenke E, Fenner M, Hirschfelder U. Vertical and sagittal growth in patients with unilateral and bilateral cleft lip and palate - A retrospective cephalometric evaluation. Cleft Palate Craniofac J 2009;46:512-20.

16. Tateishi C, Moriyama K, Takano-Yamamoto T. Dentocraniofacial morphology of 12 Japanese subjects with unilateral cleft lip and palate with a severe class III malocclusion: A cephalometric study at the pretreatment stage of surgical orthodontic treatment. Cleft Palate Craniofac J 2001;38:597-605.

17. Schultes G, Gaggl A, Kärcher H. A comparison of growth impairment and orthodontic results in adult patients with clefts of palate and unilateral clefts of lip, palate and alveolus. Br J Oral Maxillofac Surg 2000;38:26-32.

18. Meazzini MC, Donati V, Garattini G, Brusati R. Maxillary growth impairment in cleft lip and palate patients: A simplified approach in the search for a cause. J Craniofac Surg 2008;19:1302-7.

19. Sanggarnjanavanich S, Sekiya T, Nomura $Y$, Nakayama T, Hanada N, Nakamura Y. Cranial-base morphology in adults with skeletal class III malocclusion. Am J Orthod Dentofacial Orthop 2014;146:82-91.

20. Proff P, Will F, Bokan I, Fanghänel J, Gedrange T. Cranial base features in skeletal class III patients. Angle Orthod 2008;78:433-9.

21. Garrahy A, Millett DT, Ayoub AF. Early assessment of dental arch development in repaired unilateral cleft lip and unilateral cleft lip and palate versus controls. Cleft Palate Craniofac J 2005;42:385-91.

22. Brudnicki A, Bronkhorst EM, Nada R, Dudkiewicz Z, Kaminek M, Katsaros C, et al. Nasolabial appearance after two palatoplasty types in cleft lip and palate. Orthod Craniofac Res 2014;17:124-31.

23. Rajion ZA, Townsend GC, Netherway DJ, Anderson PJ, Hughes T, Shuaib IL, et al. The hyoid bone in Malay infants with cleft lip and palate. Cleft Palate Craniofac J 2006;43:532-8.

24. Ozbek MM, Memikoglu UT, Altug-Atac AT, Lowe AA. Stability of maxillary expansion and tongue posture. Angle Orthod 2009;79:214-20.

25. Shi B, Losee JE. The impact of cleft lip and palate repair on maxillofacial growth. Int J Oral Sci 2015;7:14-7.

26. Graber TM. Changing philosophies in cleft palate management. J Pediatr 1950;37:400-15.

27. Koberg W, Koblin I. Speech development and maxillary growth in relation to technique and timing of palatoplasty. J Maxillofac Surg 1973;1:44-50.

28. Nollet PJ, Katsaros C, van't Hof MA, Semb G, Shaw WC, Kuijpers-Jagtman AM. Treatment outcome after two-stage palatal closure in unilateral cleft lip and palate: A comparison with Eurocleft. Cleft Palate Craniofac J 2005;42:512-6.

29. Sundareswaran S, Thirumoorty SN. Anterior cranial base features in skeletal class III patients with maxillary recession: A cephalometric study. Orthodontics (Chic.) 2012;13:e105-15.

30. Paradowska-Stolarz A, Kawala B. Measurements of mandibular length in patients with total clefts. Dev Period Med 2014;18:110-5.

31. Sundareswaran S, Nipun CA. Glenoid fossa position in surgically repaired unilateral cleft lip and palate patients. Eur J Orthod 2015;37:386-90.

32. Hermann NV, Darvann TA, Ersbøll BK, Kreiborg S. Short mandible-A possible risk factor for cleft palate with/without a cleft lip. Orthod Craniofac Res 2014;17:106-14.

33. Singh GD, Rivera-Robles J, de Jesus-Vinas J. Longitudinal craniofacial growth patterns in patients with orofacial clefts: Geometric morphometrics. Cleft Palate Craniofac J 2004;41:136-43.

34. Laing E, Ashley P, Naini FB, Gill DS. Space maintenance. Int J Paediatr Dent 2009;19:155-62.

35. Pegelow M, Alqadi N, Karsten AL. The prevalence of various dental characteristics in the primary and mixed dentition in patients born with non-syndromic unilateral cleft lip with or without cleft palate. Eur J Orthod 2012;34:561-70.

36. Abd Rahman N, Abdullah N, Samsudin AR, Naing Mohd Ayub Sadiq L. Dental anomalies and facial profile abnormality of the non-syndromic cleft lip and palate children in Kelantan. Malays J Med Sci 2004;11:41-51.

37. Jamilian A, Showkatbakhsh R, Boushehry MB. The effect of tongue appliance on the nasomaxillary complex in growing cleft lip and palate patients. J Indian Soc Pedod Prev Dent 2006;24:136-9.

38. Zhang H, Deng F, Wang H, Huang Q, Zhang Y. Early orthodontic intervention followed by fixed appliance therapy in a patient with a severe Class III malocclusion and cleft lip and palate. Am J Orthod Dentofacial Orthop 2013;144:726-36. 